\title{
Indígenas na história do Brasil: identidade e cultura
}

Indians in the history of Brazil: identity and culture

Antonio Simplicio de Almeida Neto*

\section{Almeida, Maria Regina Celestino de \\ Os índios na História do Brasil}

Rio de Janeiro: Ed. FGV, 2010. 167p.

A Lei 11.645 de 10 de março de 2008, que torna obrigatório o estudo de história e cultura indígenas (além da africana e afro-brasileira) nos estabelecimentos de ensino fundamental e médio, público e privado, explicita algumas importantes questões sobre o ensino dessa disciplina escolar. A mais evidente é o fato de não haver esse componente curricular nos cursos de Graduação e Licenciatura em História, salvo raras exceções, o que traz uma série de implicações àqueles professores que desejam cumprir a determinação legal, pois devem suprir essa lacuna na formação pelos mais diversos meios disponíveis. Entre eles, certamente, destaca-se o livro didático - esse 'produto cultural complexo', como disse Stray -, que acaba por exercer inusitado e importante papel na formação docente.

Outro aspecto, no entanto, ganha relevância na abordagem dessa temática em sala de aula: o fato de a cultura indígena não ser a dominante em nossa sociedade, tanto que é objeto dessa legislação específica. Assim, é considerada 'a outra', diferente, diversa, exótica e estranha, frente à cultura dominante, ocidental, branca, europeia, civilizada, cristã e 'normal'. Sujeita aos estigmas classificatórios, a cultura desse 'outro' será identificada como primitiva, étnica, inferior e atrasada, será entendida como essencialista, ou seja, pura, fixa, imutável e estável, portanto, a-histórica. Dessa forma, o indígena que não se apresenta nesse suposto estado puro será considerado aculturado, não índio, sem

*Departamento de História, Universidade Federal de São Paulo. Estrada do Caminho Velho, 333, Bairro dos Pimentas, 07252-312 Guarulhos - SP - Brasil. asaneto@unifesp.br 
identidade e sem tradição, daí os índios serem representados predominantemente como figuras do passado, mortas ou em franco processo de extinção, fadados ao desaparecimento.

Embora não seja destinado especificamente a suprir a demanda desses conteúdos pelos professores da educação básica, o livro Os índios na História do Brasil de Maria Regina Celestino de Almeida apresenta importante e denso panorama da temática, dentro dos limites de um livro de bolso (coleção FGV de bolso, Série História), e bem serviria a esse propósito. Baseia-se na produção historiográfica mais recente, em novas leituras decorrentes de documentos inéditos, novas abordagens fundamentadas em novos conceitos e teorias, bem como em pesquisas interdisciplinares, e começa, justamente, pela complexa discussão sobre a concepção de cultura indígena que acabou por alijar esse grupo social da História.

Desempenhando papéis secundários ou aparecendo na posição de vítimas, aliados ou inimigos, guerreiros ou bárbaros, escravos ou submetidos nunca sujeitos da ação, uma vez dominados, integrados e aculturados -, desapareciam como índios na escrita histórica e, não à toa, estariam condenados ao desaparecimento também no presente, prognóstico derrubado pelas evidências apontadas pelo censo demográfico do IBGE de 2010, que aponta crescimento de $178 \%$ no número de indígenas autodeclarados desde 1991, bem como a existência de 305 etnias e 274 línguas.

O reconhecimento aos povos indígenas do direito de manter sua própria cultura, garantido pela Constituição de 1988, assim como sua maior visibilidade em lutas pela garantia de seus direitos, tiraram esses grupos dos bastidores da história - para usar uma imagem da própria autora -, garantindo-lhes um lugar no palco, despertando o interesse dos historiadores que passaram a percebê-los como sujeitos participando ativamente dos processos históricos. Tal percepção foi ainda favorecida pela imbricação entre história e antropologia na perspectiva de "compreensão da cultura como produto histórico, dinâmico e flexível, formado pela articulação contínua entre tradições e novas experiências dos homens que a vivenciam" (p.22), possibilitando novos entendimentos das ações dos grupos indígenas nos processos em que estavam envolvidos.

Ao discutir hibridação cultural, Canclini afirma que "quando se define uma identidade mediante um processo de abstração de traços (língua, 
tradições, condutas estereotipadas), frequentemente se tende a desvincular essas práticas da história de misturas em que se formaram”, o que torna impossível para esse antropólogo "falar das identidades como se se tratasse apenas de um conjunto de traços fixos, nem afirmá-las como a essência de uma etnia ou de uma nação". ${ }^{1}$ Nesse sentido, Almeida chama nossa atenção para o necessário entendimento das "identidades como construções fluidas e cambiáveis que se constroem por meio de complexos processos de apropriações e ressignificações culturais nas experiências entre grupos e indivíduos que interagem" (p.24), que tornou possível nova mirada dos historiadores sobre a identidade genérica imposta sobre esses grupos, a começar pela denominação 'índios', como se constituíssem um bloco homogêneo, desconsiderando não só as diferenças étnicas e linguísticas, mas também os diferentes interesses, objetivos, motivações e ações desses grupos nas relações entre si e com os colonizadores europeus que, como não poderia deixar de ser, foram se modificando com a dinâmica da colonização.

Importante ressaltar que as considerações da autora sobre cultura e identidade são fundamentais para compreender a perspectiva adotada pelos historiadores que se debruçam sobre essa temática, mas igualmente necessárias para o leitor que pretende conhecer um pouco mais sobre os índios na História do Brasil e, por que não dizer, indispensáveis aos professores do ensino básico que, tendo de se haver com o ensino de história e cultura indígenas nos estabelecimentos de ensino público e privado, deparam com toda sorte de preconceito, racismo e etnocentrismo.

Imbuída dessa concepção dinâmica de identidade e cultura, a autora nos apresenta ao longo dos seis capítulos do livro alguns dos principais debates e pesquisas acadêmicos sobre a temática, sem entrar na discussão historiográfica sobre haver ou não uma história indígena, propriamente dita, ou sobre a controversa denominação etno-história, daí a interessante solução encontrada para o título da obra: Os índios na História do Brasil.

A autora esclarece que para o estudo das relações entre os colonizadores e indígenas, já nos primeiros contatos torna-se necessário não tomar estes últimos como tolos ou ingênuos dispostos a colaborar com os portugueses em troca de quinquilharias, mas compreender seu universo cultural. Discutindo, por exemplo, a peculiar relação com o outro na cultura Tupinambá, implicada na guerra, nos rituais de vingança, escambo e casamento, nos alerta que 
"embora eles tivessem grande interesse nas mercadorias dos europeus, suas relações com estes últimos significavam também oportunidades de ampliar relações de aliança ou de hostilidade" (p.40). Da mesma forma, afirma que "eles trabalhavam movidos por seus próprios interesses, e quando as exigências começaram a ir além do que estavam dispostos a dar, passaram a recusar o trabalho" (p.42), o que se somou ao fato de que no universo cultural desse grupo o trabalho agrícola era considerado atividade feminina.

Embasada em vasta bibliografia e em fontes primárias, a autora percorre a complexidade das relações indígenas nas diversas regiões do país - capitanias de Pernambuco, Paraíba, Rio Grande, Itamaracá, Ilhéus, Bahia, Ilhéus, Espírito Santo, São Tomé, Ceará, Maranhão, Mato Grosso, Goiás, Rio de Janeiro etc. Nesse percurso, reafirma a identidade dos grupos indígenas como característica dinâmica, como é o caso dos temiminós do Rio de Janeiro, que provavelmente seriam uma construção étnica do contexto colonial, oriunda do subgrupo Tupinambá no processo de relações e interesses dos grupos indígenas e estrangeiros, pois "afinal, se a identidades étnicas são históricas e múltiplas, não há razões para duvidar de que os índios podiam adotar para si próprios e para os demais, identidades variadas, conforme circunstâncias e interesses" (p.61).

A condição de agentes históricos atribuída aos indígenas ganha evidência na análise da política de aldeamentos que, conforme demonstra Maria Regina Celestino de Almeida, possuía diferentes funções e significados para a Coroa, religiosos, colonos e índios. Para estes, poderia significar terra e proteção frente às ameaças a que estavam submetidos nos sertões, como escravização e guerras, o que não os impedia de agir conforme seus interesses e aspirações na relação com os outros grupos, não obstante as limitações de toda ordem a que estavam sujeitos nesses espaços de conformação. Dessa forma, valendo-se da legislação decorrente das políticas indigenistas, os índios aldeados "aprenderam a valorizar acordos e negociações com autoridades e com o próprio Rei, reivindicando mercês, em troca de serviços prestados. Sua ação política era, pois, fruto do processo de mestiçagem vivido no interior das aldeias. Suas reivindicações demonstraram a apropriação dos códigos portugueses e da própria cultura política do Antigo Regime" (p.87).

Nesse sentido, afirma a autora, os aldeamentos devem ser pensados como “espaços de reelaboração identitária” (p.98), seja ressignificando os rituais religiosos católicos, aprendendo a ler e escrever o português ou estabelecendo 
relações complexas e ambíguas com os diferentes grupos sociais, inclusive indígenas, segundo seus interesses.

Esse processo pode ser ainda observado na Amazônia de meados do século XVIII, quando índios tornaram-se vereadores, oficiais de câmara e militares (p.120), e se prolonga pelo século XIX, quando indígenas eram recrutados compulsoriamente para os serviços militares, notadamente a Marinha (p.147). Interessante lembrar o episódio da Guerra do Paraguai (1864-1870), na qual lutaram índios Terena e Kadiwéu, não sem utilizar diversas estratégias para escapar ao alistamento como Voluntários da Pátria. Mais tarde, no último quartel do século XX, essa participação foi evocada na reconstituição da memória desses grupos para reivindicar direitos territoriais no Mato Grosso do Sul ancorados no heroísmo e colaboração com o Estado (p.149). Sujeitos históricos no presente e no passado, condição que dialoga com as possibilidades de romper a invisibilidade indígena no passado e no presente.

NOTA

${ }^{1}$ CANCLINI, Nestor. Culturas híbridas. São Paulo: Edusp, 2008. p.23.

Resenha recebida em 20 de junho de 2012. Aprovada em 1ํ de setembro de 2012. 